\title{
Dietary diversity practice and associated factors among pregnant women in North East Ethiopia
}

\author{
Seid Aliwo ${ }^{1}$, Melkitu Fentie ${ }^{2^{*}}$, Tadesse Awoke ${ }^{3}$ and Zemichael Gizaw ${ }^{4}$
}

\begin{abstract}
Objective: Diversified food during pregnancy is the very important since it is known to affect pregnancy and birth outcomes. The aim of this study was to assess dietary diversity practice and associated factors among rural pregnant women in North East Ethiopia.

Result: A total of 647 pregnant women were participated with a response rate of $97.4 \%$. The adequate dietary diversity practice of pregnant women was found to be 31.4\% [95\% confidence interval (CI) 27.8-35.2]. Cereals were the most commonly consumed food groups. Dietary diversity practice of pregnant women was associated with maternal education [Adjusted Odds Ratio (AOR) $=2.36,95 \% \mathrm{Cl} 1.29,4.32$ ], wealth index ( $\mathrm{AOR}=1.85,95 \% \mathrm{Cl} 1.21,2.82$ ), nutrition information ( $A O R=2.51,95 \% \mathrm{Cl} 1.05,6.02)$ and Productive safety net program beneficiary (PSNP) $(\mathrm{AOR}=1.7,95 \% \mathrm{Cl}$ $1.16,2.50)$. The dietary diversity practice of pregnant women was found to be low in the study area. Maternal education, wealth status, having nutrition information and PSNP beneficiary were the determinant factors.
\end{abstract}

Keywords: Dietary diversity, Pregnant women, Jille Tumuga, North East Ethiopia

\section{Introduction}

Pregnancy is a critical period in the lifecycle during which additional nutrients are required to meet the metabolic and physiological demands as well as the increased requirements of the growing fetus [1]. So diversified dietary intake has to meet the needs of the mother as well as the products of conception [2]. Dietary diversity is the consumption of a variety of food groups over a reference period which has been accepted as an aspect of dietary quality and can indicate nutritional adequacy [3].

Diversified food during pregnancy is the most important since it is known to affect pregnancy and birth outcomes $[4,5]$. The effect of inadequate intake of nutrients during pregnancy leads to irreversible damage to the fetus that can compromise the future work capacity and survival [6-8].

\footnotetext{
*Correspondence: melkitu12@gmail.com

${ }^{2}$ Department of Human Nutrition, Institute of Public Health, College of Medicine and Health Sciences, University of Gondar, Gondar, Ethiopia Full list of author information is available at the end of the article
}

Diets of pregnant women in low and middle-income countries (LMICs) are monotonous, low quality and predominantly plant-based with little consumption of micronutrient-dense animal-source foods, fruits, and vegetables [9, 10]. The government of Ethiopia has launched National Nutrition Program and prioritized interventions like Promote maternal nutrition including adequate intake of diversified foods to improve the nutritional status of women. Even though the implementation of the above strategy, thinness and different micronutrient deficiencies are common problems during pregnancy $[11,12]$. There is limited data regarding the dietary diversity practice and factors associated during pregnancy in Ethiopia in general and specifically in rural areas. Therefore, the purpose of this study was to determine the dietary diversity practice and associated factors among rural pregnant women in Jille Tumuga district, Oromia Special Zone, Amhara region, Northeast Ethiopia.

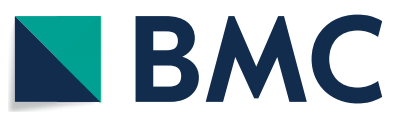

(c) The Author(s) 2019. This article is distributed under the terms of the Creative Commons Attribution 4.0 International License (http://creativecommons.org/licenses/by/4.0/), which permits unrestricted use, distribution, and reproduction in any medium, provided you give appropriate credit to the original author(s) and the source, provide a link to the Creative Commons license, and indicate if changes were made. The Creative Commons Public Domain Dedication waiver (http://creativecommons.org/ publicdomain/zero/1.0/) applies to the data made available in this article, unless otherwise stated. 


\section{Main text Method}

A community based cross-sectional study was conducted at Jille Tumuga district from March to April 2017. Jille Tumuga is a rural district found $265 \mathrm{kms}$ far from Addis Ababa, the capital of Ethiopia, $616 \mathrm{kms}$ away from Bahirdar (the capital city of the region).. The district is divided into 18 rural kebeles (smallest administrative unit in Ethiopia) and there are four governmental health centers and 21 health posts. It has a predominantly kola (Tropical Zone) agro-ecology and the altitude of the district ranges from 1000 to $2000 \mathrm{~m}$ above the sea level. Cereals, such as maize, sorghum, wheat, and barley are the main staple crops cultivated in the district. The main livestock reared are cattle and goats.

All pregnant women who lived in Jille Tumuga district for at least 6 months were eligible for the study. Sample size was estimated using the single population proportion formula [13] by considering adequate dietary diversity as $50 \%$ (since there was no similar study in the study area), 1.5 design effect and 10\% non response rate the required sample size was 634 . Since cluster sampling technique was used, all pregnant mothers in the selected cluster were included and the final sample size was 664. Clusters were Kebeles and from total kebeles, 7 were selected by simple random sampling.

An interviewer administered structured and pre-tested questionnaire was used to collect socio-demographic, maternal and health related factors, feeding \& dietary diversity practice, wealth index and food security status of pregnant women. It was first prepared in English and then translated to oromifa and translated back to English to maintain its consistency. To ensure the quality of data, pre-test was done and modifications were made accordingly. Six health extension workers and two diploma nurses were involved in data collection supervision respectively.

Tools for measuring dietary diversity was adopted from FAO guidelines for measuring minimum dietary diversity women, 2016. It was assessed by asking respondents to list all food items they consumed in the last $24 \mathrm{~h}$ preceding the survey day. A total of ten food groups were used and respondents who consumed $<5$ food groups were classified as having inadequate dietary diversity whereas those consumed $\geq 5$ food groups were classified as having adequate dietary diversity practice [14].

Household's wealth index measuring tool was adopted from EDHS 2011 [15]. It was analyzed using Principal Component Analysis (PCA) by considering the household assets, such as livestock, type of house, durable assets, productive assets and agricultural land ownership. First, variables were coded between 0 and 1 . Then variables entered and analyzed using PCA, and those variables having a communality value of greater than 0.5 were used to produce factor scores. Finally, the factor scores were summed and ranked into tertiles as poor, medium and rich.

Food insecurity was measured using FANTA household food insecurity access scale (HFIAS) tool. It is consisted of nine occurrence questions that represent a generally increasing level of severity of food insecurity (access), and nine "frequency-of-occurrence" questions. The frequency-of-occurrence question is skipped if the respondent reports that the condition described in the corresponding occurrence question was not experienced in the previous 4 weeks ( 30 days). Finally individuals were considered as food secure if they respond "no" to all of items or just experience worry but rarely; mildly food insecure if household worries about not having enough food sometimes or often/or unable to eat preferred foods; moderately food insecure if household scarifies quality more frequently, by eating a monotonous diet or undesirable foods sometimes or often and severely food insecure if household experience forced cutting back on meal size or number of meals often, and/or experiences any of the three most severe conditions [16].

The data was cheeked, coded and entered using EPI data 3.1 software and exported to SPSS version 20 statistical packages for further analysis. Data cleaning was performed. Frequencies and graphs were used to explore the data. Binary logistic regression was used to identify the confounders. Variables having p-value $<0.2$ in the binary logistic regression was fitted into the multiple logistic regression models. Adjusted odds ratio (AOR) with 95\% confidence interval (C.I) was computed to assess the presence and strength of association. Variables having p-value less than 0.05 in multiple logistic regressions were considered as significantly associated with the dependent variables. Hosmer-lemshow goodness of fit test was used for model adequacy checking and it was 0.52 .

\section{Results \\ Socio-demographic characteristics}

A total of 647 pregnant women were participated in this study with a response rate of $97.4 \%$. The mean age of the participants was $26.21( \pm 4.61)$ years. Most of the participants were married 643 (99.4\%). Majority $(68.3 \%)$ of the respondents were not educated. More than one third $(33.2 \%)$ of the respondents were poor (Table 1).

\section{Meal frequency and feeding practice}

Less than half, 284 (43.9\%) of respondents had meal frequency of four and above per day. Two hundred eighty six (44.7\%) of respondents had the habits of taking snacks. One fifth of the respondents had habit of skipping meal 
Table 1 Socio demographic characteristics of pregnant women $(n=647)$ in Jille Tumuga district Northeast Ethiopia, 2017

\begin{tabular}{|c|c|c|}
\hline Variable & Frequency (n) & Percent (\%) \\
\hline \multicolumn{3}{|l|}{ Age } \\
\hline $17-19$ & 34 & 5.3 \\
\hline $20-24$ & 180 & 27.8 \\
\hline $25-35$ & 407 & 62.9 \\
\hline$\geq 35$ & 26 & 4 \\
\hline \multicolumn{3}{|l|}{ Marital status } \\
\hline Married & 643 & 99.4 \\
\hline Widowed & 4 & 0.6 \\
\hline \multicolumn{3}{|l|}{ Religion } \\
\hline Muslim & 643 & 99.4 \\
\hline Orthodox & 4 & 0.6 \\
\hline \multicolumn{3}{|l|}{ Ethnicity } \\
\hline Oromo & 576 & 89.0 \\
\hline Amhara & 63 & 9.7 \\
\hline Argoba & 8 & 1.2 \\
\hline \multicolumn{3}{|c|}{ Educational status of pregnant women } \\
\hline No education & 442 & 68.3 \\
\hline Read and write & 60 & 9.3 \\
\hline Primary and above & 145 & 22.4 \\
\hline \multicolumn{3}{|l|}{ Educational status of husband } \\
\hline No education & 381 & 58.9 \\
\hline Read and write & 94 & 14.5 \\
\hline Primary and above & 172 & 26.6 \\
\hline \multicolumn{3}{|c|}{ Occupation of pregnant women } \\
\hline Housewife & 638 & 98.6 \\
\hline Merchant & 6 & 0.9 \\
\hline Government employee & 3 & 0.5 \\
\hline \multicolumn{3}{|l|}{ Occupation of husband } \\
\hline Farmer & 614 & 94.9 \\
\hline Merchant & 11 & 1.7 \\
\hline Government employee & 6 & 0.9 \\
\hline Daily laborer & 16 & 2.5 \\
\hline \multicolumn{3}{|l|}{ Family size } \\
\hline $1-2$ & 71 & 11.0 \\
\hline $3-4$ & 365 & 56.4 \\
\hline$>5$ & 211 & 32.6 \\
\hline \multicolumn{3}{|c|}{ Productive safety net program beneficiary } \\
\hline Yes & 275 & 42.5 \\
\hline No & 372 & 57.5 \\
\hline \multicolumn{3}{|l|}{ Food security status } \\
\hline Food secure & 425 & 65.7 \\
\hline Mildly food insecure & 18 & 2.8 \\
\hline Moderately food insecure & 193 & 29.8 \\
\hline Severely food insecure & 11 & 1.7 \\
\hline \multicolumn{3}{|l|}{ Wealth index } \\
\hline Poor & 215 & 33.2 \\
\hline Medium & 216 & 33.4 \\
\hline Rich & 216 & 33.4 \\
\hline
\end{tabular}

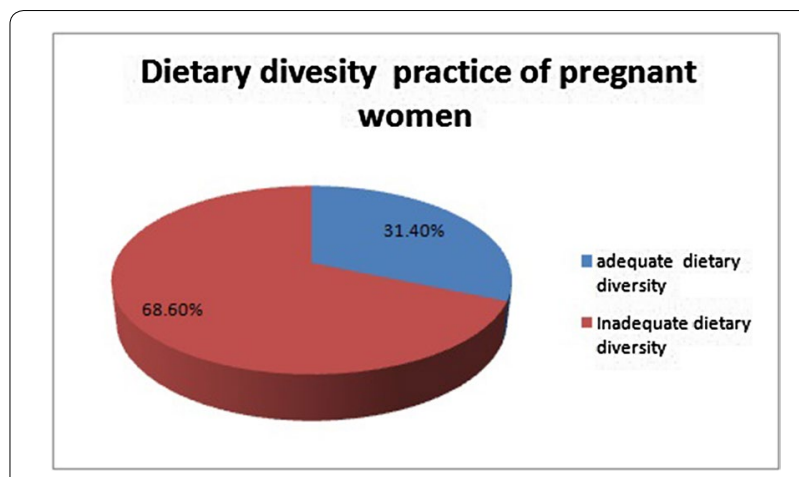

Fig. 1 Dietary diversity practice among rural pregnant women during the preceding $24 \mathrm{~h}(\mathrm{n}=647)$ in Jille Tumuga district Northeast Ethiopia, 2017

and 158 (24.4\%) of respondents had avoided some kind of food during pregnancy.

\section{Dietary diversity practice of pregnant women}

The overall prevalence of adequate dietary diversity practice among pregnant women were found to be $31.4 \%$ with (95\% CI 27.8-35.2\%) (Fig. 1).

Factors associated with dietary diversity practice of pregnant In the adjusted analysis mother's educational status, wealth index, PSNP beneficiary and nutrition information were significantly associated with dietary diversity practices of pregnant women.

The odds of dietary diversity practice was 2.36 times $(\mathrm{AOR}=2.36,95 \% \mathrm{CI} 1.29,4.32)$ higher among pregnant women who can read and write than those who had no formal education. While the odds of dietary diversity practice was $94 \%(\mathrm{AOR}=1.94,95 \%$ CI 1.24, 3.01) higher among pregnant women who had primary education and above than those having no formal education. With regard to wealth index, the odds of dietary diversity practice was $85 \%(\mathrm{AOR}=1.85$, CI 1.21, 2.82) higher in rich pregnant women than the poor pregnant women. On the other hand, the odds of dietary diversity practice was 2.58 $(\mathrm{AOR}=2.58, \mathrm{CI} 1.05,6.02)$ times higher among pregnant women who had nutrition information than their counterparts. While the odds of dietary diversity practice was $71 \%$ higher among pregnant women who are not beneficiary of productive safety net program than their counterparts (Table 2).

\section{Discussion}

Recognizing the dietary diversity practice of pregnant women is vital since it affects the health and long term productivity of the mother and the fetus. This study 
Table 2 Factors associated with dietary diversity practice of pregnant women in Jille Tumuga district, Northeast Ethiopia, 2017

\begin{tabular}{|c|c|c|c|c|}
\hline \multirow[t]{2}{*}{ Variable } & \multicolumn{2}{|l|}{ Dietary diversity } & \multirow[t]{2}{*}{ COR with $95 \% \mathrm{Cl}$} & \multirow[t]{2}{*}{ AOR with $95 \% \mathrm{Cl}$} \\
\hline & $\begin{array}{l}\text { Adequate } \\
n=203(31.4 \%)\end{array}$ & Inadequate & & \\
\hline \multicolumn{5}{|c|}{ Mothers educational status } \\
\hline No education & 119 & 323 & 1 & 1 \\
\hline Read and write & 27 & 33 & $2.22(1.28,3.85)$ & $2.33(1.28,4.26)^{*}$ \\
\hline Primary and above & 57 & 88 & $1.75(1.18,2.60)$ & $1.93(1.24,2.99)^{*}$ \\
\hline \multicolumn{5}{|l|}{ Husband education } \\
\hline No education & 126 & 255 & 1 & 1 \\
\hline Read and write & 29 & 65 & $0.90(0.55,1.46)$ & $0.78(0.46,1.34)$ \\
\hline Primary and above & 48 & 124 & $0.78(0.52,1.16)$ & $0.70(0.46,1.09)$ \\
\hline \multicolumn{5}{|l|}{ Wealth index } \\
\hline Poor & 61 & 154 & 1 & 1 \\
\hline Medium & 49 & 167 & $0.74(0.47,1.14)$ & $0.73(0.46,1.15)$ \\
\hline Rich & 93 & 123 & $1.90(1.27,2.89)$ & $1.86(1.22,2.82)^{*}$ \\
\hline \multicolumn{5}{|l|}{ No of pregnancy } \\
\hline$\leq 3$ & 113 & 250 & $1.46(0.855,2.505)$ & $1.09(0.57,2.07)$ \\
\hline $4-5$ & 69 & 126 & $1.77(1.002,3.137)$ & $1.49(0.80,2.80)$ \\
\hline$\geq 6$ & 21 & 68 & 1 & 1 \\
\hline \multicolumn{5}{|l|}{ ANC follow up } \\
\hline Yes & 8 & 42 & 1 & 1 \\
\hline No & 195 & 402 & $2.54(1.17,5.53)$ & $1.66(0.61,4.46)$ \\
\hline \multicolumn{5}{|l|}{ Nutrition information } \\
\hline No & 10 & 55 & 1 & 1 \\
\hline Yes & 193 & 389 & $2.73(1.36,5.47)$ & $2.55(1.06,6.10)^{*}$ \\
\hline \multicolumn{5}{|l|}{ Nutritional status } \\
\hline Undernourished & 50 & 140 & 1 & 1 \\
\hline Normal & 153 & 304 & $1.40(0.96,2.05)$ & $1.42(0.94,2.12)$ \\
\hline \multicolumn{5}{|c|}{ Age of pregnant women } \\
\hline $17-19$ & 8 & 26 & $1.3(0.37,4.54)$ & $1.51(0.47,4.88)$ \\
\hline $20-24$ & 56 & 124 & $1.9(0.68,5.30)$ & $1.88(0.63,5.59)$ \\
\hline $25-34$ & 134 & 273 & $2.06(0.76,5.60)$ & \\
\hline$\geq 35$ & 5 & 21 & 1 & 1 \\
\hline \multicolumn{5}{|l|}{ PSNP beneficiary } \\
\hline Yes & 64 & 211 & 1 & 1 \\
\hline No & 139 & 233 & $1.96(1.38,2.79)$ & $1.72(1.17,2.52)^{*}$ \\
\hline
\end{tabular}

*indicates variables which were statistically significant in multi-variable analysis

aimed at assessing the magnitude of adequate dietary diversity practice and its associated factors among pregnant women in Jille Tumuga district. The adequate dietary diversity practice of rural pregnant women found to be $31.4 \%$. This finding is lower than the study conducted in Bangladesh 37\% [17]; Togo 45\% [18] and Northern Ghana 46.1 [19]. This difference may be due to socio demographic factors. In this study most of the participants had lower educational level compared with aforementioned studies, which could affect mother's knowledge and practice of dietary diversity. Moreover, the study subjects of the current study had larger family size in which food sharing habit of large sized families is high and so that pregnant women may not get diversified foods as required. Most of the study participants of this study were also house wives whom could not generate money by themselves so it might affect their food purchasing power and further affect their dietary diversity practice.

This study showed that the odds of adequate dietary diversity practice was two and more times higher in pregnant women who can read and write than those having 
no formal education. While the odds of dietary diversity practice was $94 \%$ higher among pregnant women who had primary education and above than those having no formal education. This showed that when educational status of a pregnant women increased, their dietary diversity practice showed a significant advancement This finding is also supported by studies conducted in Nigeria, Rural Bangladesh, Kenya and Ghana [17, 20-23]. This might be due to the contribution of education in giving information about the importance of diversified diet consumption. On the other hand educated women can have better employment opportunity and income which can further improve their household food security status and consumption of diversified food.

According to this study dietary diversity was associated with wealth status of the household. There is increased odds of dietary diversity practice by $85 \%$ in rich pregnant women than the poor. This finding is in line with study conducted in Bangladesh, Ghana and Kenya [20, 23, 24]. This could be due to the fact that rich households will have access to a variety of food and the dietary practice of pregnant women in this household will be improved.

In addition, those who are not beneficiary of productive safety net program were $71 \%$ more likely to practice adequate dietary diversity than their counter parts. This might be due to PSNP is aimed for chronically food insecure households and these households food purchasing power and access to a variety of food is limited and cereal based monotonous diet is common.

This study revealed that having information about nutrition is significantly associated with the dietary diversity practice of pregnant women. The odds of dietary practice were $51 \%$ increased in those who got nutrition information than their counter parts. This is also supported by study conducted in East Wollega Zone, Ethiopia [25] and Gondar [26] in which nutrition information was important for good nutritional practices. This may be due to the fact that those who get information about nutrition will have better knowledge and understanding to practice diversified diet than those who do not.

Over all dietary diversity practice was low in the study area. Educational status of mothers, wealth status and nutrition information and PSNP beneficence were factors associated with adequate dietary diversity practice of pregnant mothers.

Multi-sectoral collaboration is needed to enhance the dietary diversity of pregnant women by promoting women's education, strengthening sustainable income generating activities and saving strategies to improve the wealth status of pregnant women. In addition, it is better to advocate nutrition education regarding dietary diversity during pregnancy.

\section{Limitation}

We didn't consider the amount of food consumed that may not accurately reflect their past feeding experience. In addition, there might be social desirability bias during answering wealth index questions.

\begin{abstract}
Abbreviations
ANC: ante natal care; AOR: adjusted odd ratio; Cl: confidence interval; COR: crude odd ratio; DDS: Dietary Diversity Score; EDHS: Ethiopia Demographic and Health Survey; EPI DATA: Epidemiological Data; FANTA: Food and Nutrition Technical Assistance; FAO: Food and Agriculture Organization; HFIAS: Household Food Insecurity Access Scale; LMICs: Low and Middle Income Countries; MDD-W: Minimum Dietary Diversity for Women of reproductive age; OR: odd ratio; PCA: Principal Component Analysis; PSNP: productive safety net program; SD: standard deviation; SGA: small for gestational age; SNNPR: South Nation Nationality Peoples Region; SPSS: Statistical Package for Social Science; UNICEF: United Nation International Children Emergency Fund; WHO: World Health Organization.
\end{abstract}

\section{Authors' contributions}

SA contributed in the generation of the topic, preparation of proposal, data collection, analyses and development of the manuscript. ZG, MF and TA contributed in reviewing the proposal, data analysis and development of the manuscript and critical review of final manuscript. All authors read and approved the final manuscript.

\section{Author details \\ ${ }^{1}$ Oromia Special Zone Health Department, Amhara Region Health Bureau, Kemise, Ethiopia. ${ }^{2}$ Department of Human Nutrition, Institute of Public Health, College of Medicine and Health Sciences, University of Gondar, Gondar, Ethio- pia. ${ }^{3}$ Department of Epidemiology and Biostatistics, Institute of Public Health, College of Medicine and Health Sciences, University of Gondar, Gondar, Ethiopia. ${ }^{4}$ Department of Environmental and Occupational Health and Safety, Institute of Public Health, College of Medicine and Health Sciences, University of Gondar, Gondar, Ethiopia.}

\section{Acknowledgements}

The researchers want to acknowledge in advance the Jille Tumuga district administrative, Jille Tumuga district health office, respective Kebele administrations, study participants, data collectors, supervisors and Jille Tumuga district health extension workers.

\section{Competing interests}

The authors declare that they have no competing interests.

\section{Availability of data and materials}

Data will be available up on the request of the corresponding author.

\section{Consent for publication}

Not applicable.

\section{Ethics approval and consent to participate}

Ethical clearance was obtained from Ethical Review Board of University of Gondar, College of Medicine and Health Sciences, Institute of Public Health (Ref.No/IPH/2478/2017) prior to data collection. Written informed consent was obtained from each study participant after the purpose of the study explained. Pregnant women who were not volunteer to continue from the beginning or from any part of the interview were respected to do so. Privacy, anonymity and strict confidentiality were maintained during the interview process. Nutrition education about dietary diversity was given to all subjects.

\section{Funding}

No funding was obtained for this study.

\section{Publisher's Note}

Springer Nature remains neutral with regard to jurisdictional claims in published maps and institutional affiliations. 
Received: 28 January 2019 Accepted: 22 February 2019

Published online: 07 March 2019

\section{References}

1. Broughton FP. Maternal physiology. In: Edmonds DK, editor. Dewhurst's textbook of obstetrics and gynaecology. Oxford: Blackwell Publishing; 2007

2. Williamson CS. Nutrition in pregnancy 2006 British Nutrition Foundation Nutrition Bulletin, vol. 31. London: British Nutrition Foundation; 2006. p. 28-59.

3. Becquey E, Capon G, Martin-Prével Y. Dietary diversity as a measure of the micronutrient adequacy of women's diets: food and nutrition technical assistance II project. Academy for Educational Development; 2009.

4. Cuco G, Arija V, Iranzo R, Vila J, Prieto MT, Fernandez-Ballart J. Association of maternal protein intake before conception and throughout pregnancy with birth weight. Acta Obstet Gynecol Scand. 2006;85(4):413-21.

5. Savy M, Martin-Prével Y, Sawadogo P, Kameli Y, Delpeuch F. Use of variety/diversity scores for diet quality measurement: relation with nutritional status of women in a rural area in Burkina Faso. Eur J Clin Nutr. 2005:59:703-16. https://doi.org/10.1038/sj.ejcn.1602135.

6. Loaiza E. Maternal nutritional status. DHS Comparative Studies No.24. Calverton: Macro International Inc; 2002

7. Castrogiovanni P, Imbesi R. The role of malnutrition during pregnancy and its effects on brain and skeletal muscle postnatal development. Funct Morphol Kinesiol. 2017;2:30

8. Organization, W.H. Maternal and child health and nutrition fact sheet. 2009-2010.

9. Darnton-Hill I, Mkparu UC. Micronutrients in pregnancy in low- and middle-income countries. Nutrients. 2015;7:1744-68.

10. Lee SE, Talegawkar S, Merialdi M, Caulfield LE. Dietary intakes of women during pregnancy in low- and middle-income countries. Public Health Nutr. 2013;16:1340-53.

11. Central Statistical Agency (CSA) and ICF. Ethiopia Demographic and Health Survey 2016. Addis Abab: CSA and ICF; 2016.

12. Ethiopia, F.D.R.o. National nutrition program. 2016-2017.

13. Degu G, Tessema F. Biostatistics lecture note for health science students. University of Gondar In collaboration with the Ethiopia Public Health Training Initiative, The Carter Center, the Ethiopia Ministry of Health, and the Ethiopia Ministry of Education; 2005.

14. FAO and FHI 360, Minimum Dietary Diversity for Women: A Guide for Measurement, in the Food and Agriculture Organization of the United
Nations and USAID's Food and Nutrition Technical Assistance III Project (FANTA), managed by FHI 360 Rome; 2016.

15. Lamberti $\mathrm{LM}$, Fischer Walker $\mathrm{CL}$, Black RE. Zinc deficiency in childhood and pregnancy: evidence for intervention effects and program responses. World Rev Nutr Diet. 2016:115:125-33.

16. Coates J, Swindale A, Bilinsky P. Household Food Insecurity Access Scale (HFIAS) formeasurement of household food access: indicator guide (v. 3). Washington, DC: Food and NutritionTechnical Assistance Project, Academy for Educational Development; 2007. http://www.fantaproject.org. Accessed Mar 2017.

17. Shamim, et al. Pregnant women diet quality and its sociodemographic determinants in Southwestern Bangladesh. Food Nutr Bull. 2016;37(1):1426. https://doi.org/10.1177/0379572116632137.

18. Tchaou MN, Abalokoka EY, Kodjo AD, Lamboni C. Nutritional profile of pregnant women in the bassar prefecture (NORTHWEST OF TOGO). REV CAMES. 2016:4(01):2424-7235.

19. Saaka M et al, Dietary Diversity Is Not Associated with Hematological Status of Pregnant Women Resident in Rural Areas of Northern Ghana. J Nutr Metab. 2017; 10. Article ID 8497892. https://doi.org/10.1155/2017/84978 92.

20. Klemm R, et al. Dietary diversity is low and associated with nutritional status of women in early pregnancy in rural Bangladesh. Eur J Nutr Food Saf. 2015. https://doi.org/10.9734/ejnfs/2015/20886.

21. Kever RT, et al. Knowledge and attitude of pregnant Women towards dietary practices in Yerwa Clinic, Maiduguri Metropolitan Council; Borno State Nigeria. J Res Nurs Midwifery (JRNM). 2015;4(1):12-9. https://doi. org/10.14303/jrnm.2014.027.

22. Zakaria H. Socio-economic determinants of dietary diversity among women of child bearing ages in Northern Ghana. Food Sci Qual Manage. $2014 ; 34$.

23. Kiboi W, et al. Determinants of dietary diversity among pregnant women in Laikipia County, Kenya: a cross-sectional study. BMC Nutr. 2017;3:12. https://doi.org/10.1186/s40795-017-0126-6.

24. Saaka M. Maternal dietary diversity and infant outcome of pregnant women in Northern Ghana. Int J Child Health Nutr. 2012;1:148-56.

25. Daba $\mathrm{G}$, et al. Assessment of nutritional practices of pregnant mothers on maternal nutrition and associated factors in Guto Gida Woreda, East Wollega Zone. Ethiopia. Sci Technol Arts Res J. 2013;2(3):105-13. https:// doi.org/10.4314\%2Fstar.v2i3.98748.

26. Alemayehu MS, Tesema EM. Dietary Practice and Associated Factors among Pregnant Women in Gondar Town North West, Ethiopia, 2014. Int J Nutr Food Sci. 2015;4(6):707-12. https://doi.org/10.11648/j.jijfs.20150 406.27
Ready to submit your research? Choose BMC and benefit from:

- fast, convenient online submission

- thorough peer review by experienced researchers in your field

- rapid publication on acceptance

- support for research data, including large and complex data types

- gold Open Access which fosters wider collaboration and increased citations

- maximum visibility for your research: over 100M website views per year

At BMC, research is always in progress.

Learn more biomedcentral.com/submissions 